\title{
La reconciliación de las comunidades
}

\author{
Andrew $\mathrm{H}$ amilton* \\ Jesuit Theological College, \\ Melbourne, Australia.
}

La historia de la Iglesia es una historia de conflictos. Actualmente éstos se concentran en pequeñas comunidades cuya fe es esencial a su existencia, pero que viven en tensión con la Iglesia local en las parroquias o en las diocesis.

En este art́culo quisiera analizar cómo deberíamos enfocar este tipo de connlictos y lo que está implicado en el problema de la reconciliación. En la primera parte vamos a describir un tipo de pequeña comunidad y los conflictos que puede generar. En la segunda parte, analizaremos cómo abordar el tema de la unidad de la Iglesia, pues desde ahí suele buscarse una solución -aunque de forma no muy adecuada- a tales conflictos. Para ello nos apoyaremos en la teología de Cipriano de Cartago, cuyo pensamiento - comprendido en su contexto- proporciona material para una rica reflexión.

\section{Comanidades en tensión}

En cualquier parroquia o diócesis suele darse una diversidad de grupos. Al nivel parroquial puede haber carismáticos, neocatecúmenos, grupos de Justicia y Paz... A un nivel que va más allá de la parroquia puede haber grupos del tipo Opus Dei, grupos en que se acoge a homosexuales... Estos grupos, que se comprenden a sI mismos como católicos, a veces se adaptan fácilmente a la comunidad católica más amplia, pero a veces se mantienen en tensión con ella.

- El P. Andrew Hamilton, S.J., profesor de teologfa, pas6 varios meses en los años 199! y 1992 acompariando a grupos de repatriados en El Salvador. De ahí proviene su conocimiento de las comunidades de base y de los conflictos eclesiales de que habla en el artículo, y su reflexión -desde la teología de Cipriano- sobre cómo solucionar tales problemas. 
Entre estos grupos, unos se caracterizan por ser advenedizos, es decir, porque han llegado a la partoquia o a la diócesis "desde fuera", y viven en un área geográfica bien delimitada. Suelen establecerse, por lo general, en regiones de grandes movimientos de población. Suelen ser comunidades de refugiados que han huido de la violencia o de la persecución, o grupos que se han asentado sin previa autorización en los suburbios de las ciudades. Este es el tipo de comunidades cuyas características deseamos describir ahora

Ante todo hay que destacar que estos grupos han llegado a configurarse como comunidad movidos por sus propias necesidades o sus luchas, y por ello se comprenden a sí mismos como Iglesia de los pobres. Si se los compara con la población ubana y campesina de la Iglesia local en que están ubicados, son, normalmente, de recursos más bajos, sus lugares de celebración de culto son más humildes y sus festividades más modestas. Más aún, como lo que los ha movido a desplazarse a todos ellos es la necesidad, las diferencias entre ricos y pobres dentro de la comunidad son generalmente menos pronunciadas que en las iglesias vecinas.

Muchas de estas comunidades han encontrado su propia identidad al reflexionar el evangelio en común. Para ellas, por lo tanto, es algo natural comprender su vida como una expresión actual del evangelio. Al igual que las ordenes religiosas o que los puritanos que se establecieron en el nuevo mundo huyendo de la persecución, estas comunidades reconocen en su propia historia lo que aparece en la historia de salvación. En El Salvador, por ejemplo, muchas comunidades se comprenden como Iglesia de los máruires. Pueden, por tanto, invocar a Monseñor Romero como santo y márit, quien hasta el final vivió el evangelio y otorga validez a la vida y a los valores de sus comunidades.

Como en el caso de los puritanos, los miembros de estas comunidades no distinguen con claridad entre principios religiosos, pollticos y económicos, y ello es asi porque su identidad cristiana la han encontrado precisamente en las decisiones que tuvieron que tomar para sobrevivir, y no meramente en los aspectos religiosos de la existencia. Y cuando han tenido que huir de la represión del Estado, los problemas de supervivencia son inevitablemente de naturaleza política. Por ello, fe y actitudes políticas están inevitable e íntimamente unidas. La reflexión basada en la fe estimula accitudes políticas bien definidas, lo cual a su vez configura la comprensión de la fe de la comunidad.

La dificultad que tienen estas comunidades en separar fe y actiudes políticas no surge, pues, primariamente de una teorla abstracta, sino que refleja una experiencia en la cual la fe ha sido determinante para tomar decisiones cruciales que han configurado la vida de la comunidad, y que, a su vez, ha estado determinada por decisiones esencialmente políticas. 


\subsection{Concepto de Iglesia}

La experiencia típica de estas comunidades se expresa con frecuencia en un concepto de Iglesia, que tiene rasgos característicos propios.

En primer lugar, como ese concepto ha surgido desde su propia lucha por sobrevivir, "Iglesia" para ellas es ante todo su propia comunidad No es que nieguen la imporancia de una Iglesia más amplia, pero su propia historia y su apremiante necesidad de sobrevivir da como resultado que tengan pocos puntos de contacto con la Iglesia del lugar en que se han establecido.

También algunos recuerdos importantes las llevan a identificar la Iglesia con su propia comunidad. El recuerdo del haber tenido que huir en medio del terror, el recuerdo de sus mártires, de cómo su comunidad fue creciendo alrededor de la reflexión del evangelio, de las decisiones que han configurado la comunidad..., todo ello les otorga identidad propia como Iglesia, y las puede distinguir también de otros grupos dentro de la Iglesia que no comparten o valoran esos recuerdos.

Este fuerte énfasis en la comunidad local, sin embargo, queda a menudo matizado por dos cosas. En primer lugar, una comunidad que ha surgido en medio de un conflicto político es normal que permanezca identificada con el pueblo cuyos sufrimientos ha compartido. Por lo tanto, la comunidad local representa al pueblo entero en su lucha por la justicia y la libertad. En segundo lugar, tal como ocurre tambiên en las congregaciones religiosas, estas comunidades se consideran, por lo general, estrechamente ligadas a otras semejantes. En El Salvador, por ejemplo, una comunidad que lleva el nombre de Monseñor Romero puede considerar fácilmente como comunidades hermanas a la Comunidad Segundo Montes, a la Ignacio Ellacuria u otras que tienen nombres de mártires. El modo como la comunidad local se identifica como Iglesia transciende, por lo tanto, los límiles de la parroquia, de la diócesis y aun de la Iglesia nacional.

El segundo aspecto de su comprensión de lo que es Iglesia es el énfasis que ponen en los problemas éticos. Las difíciles decisiones que han influido en la vida de la comunidad sobre si huir de sus poblados, por ejemplo, o rebmar a ellos, sobre si y cómo responder a la violencia han sido decisiones de lipo práxico. Por esa razón, cuando leen la Biblia y celebran la liturgia su mayor preocupación está en las consecuencias prácticas del seguimiento de Jesús. Tanto la celebración de los sacramentos como la religiosidad tradicional están al servicio de la vivencia práctica del evangelio.

Finalmente, en estas comunidades, cl liderazgo es con frecuencia de tipo carismático más que institucional. Dado que sus líderes -que normalmente carecen de educación formal一, surgieron durante los tiempos más difíciles, su autoridad es persorial y depende del reconocimiento de la comunidad. $Y$ alla 
donde los dirigentes son de tipo clerical, su liderazgo será eficaz en la medida en que antes hayan compartido las situaciones difíciles de la comunidad.

\subsection{Fuentes de tensión}

Esta descripción de las pequeñas comunidades puede esclarecer las tensiones que surgen entre ellas y la totalidad de la Iglesia local. Las comunidades, en efecto, acentúan lo local, lo comunitario, lo ético, lo popular y lo carismálico en sus estructuras y actitudes, mientras que la Iglesia a su alrededor en su vida y autocomprensión pone mayor énfasis -comprensiblemente- en lo religiosista, lo sacramental e institucional. A dos diferentes experiencias de Iglesia corresponden dos diferentes comprensiones -implicítas- de lo que es Iglesia, con lo cual está también dada la posibilidad para las incomprensiones y las divisiones.

En primer lugar, es comprensibic que cualquier grupo ya establecido entre en algún tipo de tensión con un grupo - nuevo y con características distintasque se establece dentro de sus límites. Es bien sabido que esos grupos nunca son bienvenidos por sus huéspedes. Cuando, por ejemplo, se lleva a cabo un proyecto de vivienda mínima en los límites de una parroquia ya establecida, es muy diff́cil que coexistan ambos grupos: el grupo más pobre se siente fuera de lugar en la Iglesia, mientras que el grupo establecido no se siente a gusto con los recién llegados.

Esta comprensible tensión aumenta cuando la Iglesia establecida no hace ningún esfuerzo especial para acoger a la nueva comunidad, lo cual puede llevar a un conflicto abierto al no mostrar respelo por la historia de los recién llegados, esperando simplemente que se asimilen a ellos y a sus costumbres.

Una segunda fuente de conflictos está en las experiencias radicalmente distintas de lo que significa ser "Iglesia", a lo cual ya me he referido antes. Estas experiencias crean diferentes comprensiones y expectativas de lo que significa ministerio y predicación. Así, la nueva comunidad y la Iglesia local pueden diferir en sus juicios sobre cuán autónomas deben ser las pequeñas comunidades dentro de la Iglesia. Estas últimas se han constituido como comunidades cristianas y han forjado sus líderes al tomar -lodos juntos- decisiones de vida y muerte. Por esa razón, el que los líderes de la otra Iglesia ya establecida, nombren o reemplacen a sus propios líderes genera tensión. Y, a su vez, con frecuencia esta resistencia es vista por las comunidades establecidas como expresión de una actitud cismática, orgullosa y terca.

Un tercer tipo de tensiones se genera cuando la Iglesia establecida y las pequeñas comunidades asumen posturas políticas diferentes, especialmente cuando los miembros de la lglesia establecida no son conscientes de sus propias posturas políticas. Ass, pueden creer que, cuando las pequeñas comunidades identifican el evangelio con la lucha contra la injusticia, están subordinando la 
fe a la política. Por otra parte, las nuevas comunidades pueden ver indicios de una opción política, aunque en forma inconsciente, en el lenguaje espiritualista de las comunidades establecidas.

Este tipo de conflictos puede aumentar cuando los líderes de la Iglesia jerárquica y los de las pequeñas comunidades ya se han distanciado unos de otros con ocasión de importantes decisiones prácticas. En El Salvador, por ejemplo, los Ifderes eclesiásticos apoyaron un conjunto de propuestas que permitieron a los refugiados regresar de Honduras, pero las comunidades tomaron su propia decisión y prefirieron seguir sus propios planes. Y tomar esa decisión fue crucial para establecer su identidad como comunidad de fe. Esta cierta autonomía con respecto a la jerarquía en cuestiones de la vida diaria nuye fácilmente hacia otras áreas, pues aunque sea fácil distinguir conceptualmente entre actividades eclesiales y actividades humanitarias de la Iglesia, en la práctica, ambas se mezclan.

Una cuarta fuente de conflictos puede ser la historia de las relaciones entre la comunidad y la Iglesia oficial. Algunas pequentas comunidades creen que han sido abandonadas por la Iglesia oficial. En una guerra civil, por ejemplo, algunas diócesis retiraron el apoyo pastoral a las zonas controladas por uno de los bandos. Si las comunidades encontraron su propia identidad durante ese tiempo de abondono, probablemente resentiran cualquier intento posterior de normalizar su siluación sin ser consultadas previamente.

Una última fuente de tensión puede ser, paradójicamente, el ecumenismo. Es frecuente que las pequefias comunidades hayan sufrido junto con otros grupos cristianos y hayan buscado y recibido apoyo de otras iglesias cristianas. Por ello, pueden sentir una unidad más fuerte con esas comunidades que con otros grupos de la Iglesia local, que han sobrevivido sin problemas durante la represión. En medio de conflictos es natural que busquen orientación y liderazgo en la comunidad cristiana más amplia, no sólo en la católica.

\section{Cipriano y la unidad de la Iglesia}

Quienes hoy reflexionan sobre este lipo de conflictos con frecuencia hacen suyo - aun sin saberlo- un pequeño tratado de Cipriano de Cartago, aunque hoy suele ser normal presentar en forma restrictiva y estrecha la teología de Cipriano. A continuación vamos a presentar un breve resumen de su teologfa de la Iglesia tal como la expone en su obra De Ecclesiae Unitate.

\subsection{Resumen de la argumentación de Cipriano}

Lo primero que afima Cipriano es que nuestro único acceso a Dios es a través de la Iglesia. Por consiguiente, separarnos de la Iglesia es separamos de Dios: 
Todo el que se separa de la Iglesia se une a una adúltera, se aleja de las promesas de la Iglesia (...) No puede tener a Dios por padre quien no tiene a la Iglesia como madre'.

Elabora después cómo se fundamenta la unidad. La unidad de los cristianos con la Iglesia está representada por la unidad de los apóstoles con Pedro:

Decidió con su propia autoridad quc el origen de la unidad proviniese de uno solo. Cierto que los demás apóstoles eran lo que era Pedro, estaban dotados como Pedro de la misma dignidad y poder, pero el principio nace de la unidad y se otorga el primado a Pedro y para manifestar que es una la Iglesia y la Cátedra de Jesucristo².

Prosigue Cipriano y afirma que la unidad de la Iglesia está basada en la unidad de los obispos entre ellos y en la unidad del pueblo con el obispo.

Debemos mantener y defender con toda energía esta unidad, mayormente los obispos, que estamos al frente de la Iglesia, a fin de probar que el mismo episcopado es uno e indivisible'.

La consecuencia de basar la unidad de la Iglesia en la unidad en torno a los obispos es que quienes se separan del obispo se separan de Cristo. Cipriano pregunta retóricamente:

¿Acaso piensan que está Cristo con ellos cuando se hubieren reunido los que se reúnen fuera de la Iglesia con Cristo?

La conclusión de Cipriano es que aun aquellos que tienen gran autoridad moral por haber permanecido fieles en las persecuciones están perdidos si no permanecen en unión con la Iglesia.

No pueden, pues, estar con Dios quienes no hicieron por estar unidos dentro de la Iglesia de Dios. Aunque hayan entregado la vida a las llamas, ne tendrán la corona de la fe, si no el castigo de su deslealtads.

En conclusión, para Cipriano unidad con Dios, unidad con Cristo, unidad con la Iglesia y unidad con el obispo son inseparables. Pero hay que recalcar que describe la unidad de la Iglesia en términos sacramentales muy ricos, mientras que es frecuente que quienes apelan a él para resolver conflictos dentro de la Iglesia interpretan su pensamiento en términos canónicos, lo cual reduce indebidamente la riqueza de su teología. Suelen aducir, en efecto, el argumento citado simplemente para insistir en que las pequeñas comunidades deben reconocer la autoridad del obispo local y se deben incorporar a las estructuras de la diócesis. La unidad de la Iglesia quedaría entonces reducida al sometimiento al obispo.local y al Papa.

La teología de Cipriano, sin embargo, es mucha más rica y útil para quien quiera reflexionar sobre los conflictos al interior de la Iglesia. Esto queda muy 
claro al analizar la compleja situación de su propia Iglesia y cómo enfrentó Cipriano el problema, tal como aparece en otros tratados suyos y en sus cartas.

\subsection{Cipriano en su contexto}

La situación de la iglesia de Cipriano fue turbulenta, porque sufrí persecuciones y porque con frecuencia surgieron conflictos entre los diversos grupos dentro de ella. Varios de estos grupos pueden ser tipificados de acuerdo a cómo les afectó la persecución. En primer lugar, Cipriano menciona con frecuencia a los mártires que fueron asesinados por su fidelidad durante la persecución. Están poderosamente presentes en la memoria de la Iglesia y son considerados como su gloria. En segundo lugar, menciona a aquellos que sufrieron durante la persecución, pero sobrevivieron -a menudo quedaron arruinados económicamente y con la salud destruida. Estos son los confesores. En tercer lugar, Cipriano alude a muchos otros que no fueron afectados por la persecución.

La memoria de los mártires más la coexistencia dentro de la Iglesia de los confesores y de aquellos que sobrevivieron a la persecución sin ningún daño constituyeron una poderosa fuente de tensiones en la Iglesia de Cipriano, como se echa de ver cuando se analiza más de cerca la realidad de aquellos que sobrevivieron a la persecución sanos y salvos. Y también entre éstos hay varios grupos.

Un primer grupo importante eran los lapsi, es decir, los que renunciaron a su fe por temor a la persecución. Algunos de ellos habían renegado libremente, otros hablan ofrecido sacrificios sólo después de haber sido torturados, mientras que otros compraron certificados que mostraban que hablan sacrificado, aun cuando no lo hubieran hecho realmente. Un segundo grupo habla escapado a la persecución, pero sin comprometer su fe. Algunos, incluyendo de manera notable al mismo Cipriano, huyeron de la ciudad. Otros se quedaron -con riesgos-, pero no fueron alcanzados por la persecución. Es comprensible, pues, que las relaciones entre estos grupos fueran tensas.

Cipriano distingue también diversos grupos de cristianos según el lugar que ocupaban en la Iglesia. Menciona con frecuencia a los pobres y a las viudas que recibían ayuda de la Iglesia, quienes, por lo tanto, quedaban más desprotegidos con la confiscación de bienes y con la pérdida de pertenencia a la Iglesia durante la persecución.

En este contexto, Cipriano escribe constantemente a los obispos y al clero locales, quienes tenían la responsabilidad de mantener en el día a día la paz dentro de la Iglesia. Por lo que toca a los obispos locales, tenía que tratar con aquellos que habran establecido comunidades rivales. Algunos exiglan que los dirigentes eclesiales fuesen nombrados en base a su heroica resistencia durante la persecucion, mientras que otros, los lapsi. que hablan renegado, eslaban furio- 
sos porque - lógicamente- habían sido retirados de sus posiciones de autoridad. Finalmente, Cipriano tenía que tratar con los líderes de las grandes iglesias, muy especialmente con el obispo de Roma, a quien Cipriano vio como centro de unidad eclesial a pesar de desacuerdos ocasionales, aunque fueron graves y públicos.

Recordar este contexto tan complejo es importante, pues Cipriano dirigirá su tratado sobre la unidad de la Iglesia sólo a uno de estos grupos: a aquellos que habian establecido iglesias rivales. Alaba la unidad con el obispo contra aquellos que habían fundado una Iglesia completamente cismática, pero no considera el principio de unidad como recela suficiente para reconciliar a los grupos, a menudo conflictivos, dentro de su Iglesia. Asf, para comprender adecuadamente su visión de la unidad que debe exislir en la Iglesia debemos ampliar el análisis en base a otros escritos suyos, sus tratados y sus cartas a la Iglesia.

\subsection{El fundamento de la unidad}

Para Cipriano, la unidad de la Iglesia refleja, en primer lugar, una unidad más profunda, la unidad del evangelio de Jesucristo. La obediencia al evangelio es el criterio según el cual hay que medir los diferentes aspecios de la vida de la Iglesia.

Cuando reflexiona sobre el martirio, por ejemplo, insiste tajantemente en la prioridad del evangelio.

Pues si el evangelio tiene establecido una cosa, y los mártires determinan otra, oponiéndose al evangelio, los mártires correrán doble peligro. En efecto, por una parte, toda autoridad del evangelio quedará al fin quebrantada y por los suelos, si otra decisión nueva pudo sobreponerse'.

Esta obediencia a la ley del evangelio también da luz sobre el modo como los diferentes grupos dentro de la Iglesia deben relacionarse unos con ouros. Cuando quiere animar a los diáconos a visitar a los confesores que están en prisión, apela al evangelio.

Había pensado, por cierto, que los presbíteros y diáconos que están presentes os debran advertir e instruir plenamente sobre la ley evangélica, como se ha hecho anteriomente en tiempos de mis antecesores; los diáconos iban a la cárcel y regulaban la demanda de los mártires con sus consejos y preceptos de la Escritura?.

\subsection{Una base concreta de unidad}

Para Cipriano, la obediencia al evangelio no es criterio puramente teórico ni abstracto. Cree, más bien, que la obediencia se configura según las exigencias del seguimiento de Cristo en un tiempo y un lugar determinados. En lenguaje de 
la teologla actual, se podria decir que la obediencia al evangelio implica escudrinar los signos de los tiempos. Para Cipriano no hay duda de que, en los tiempos difíciles que le tocó vivir, obediencia al evangelio significa esencialmente fidelidad en tiempo de persecución. De modo semejante, la unidad de la Iglesia no es algo abstracto ni aislado. La unidad es algo importante porque refleja y fomenta la fidelidad en la persecución. Para Cipriano, pues, tanto la unidad, como la teología de la Iglesia giran alrededor del eje de la persecución. Esto es lo que está en el fondo de las imágenes que ofrece de la vida cristiana y del modo de reflexionar sobre la fe cristiana.

La imagen con que describe la vida cristiana es la del combate y la disciplina militar. La batalla con que culmina la vida cristiana es el martirio. Esto es lo que escribe a los confesores:

A estos principios gloriosos de vuestra confesión y a estos augurios de una campaffa vicloriosa se ha juntado la fidelidad a la disciplina; la hemos observado en el vigor de vuestra carla".

También describe a Jesucristo como soldado y como mártir:

No nos hemos inscrito, en efecto, en la milicia para pensar sólo en la paz y zafamos y rehusar el servicio, cuando el Señor fue el primero en practicar ese servicios.

La persecución configura no solo las imágenes con que Cipriano describe la vida cristiana, sino también la comprensión de sus exigencias. Por ejemplo, critica el apego a las riquezas no por razones ascéticas generales, sino porque lleva a que los ricos traicionen a Cristo en la persecución.

A muchos alucinó el amor desordenado a sus bienes, y no pudieron estar prontos y desembarazados para la retirada aquellos a quienes tentan atados como con grillos sus haberes ${ }^{10}$.

Para Cipriano, pues, la unidad de la Iglesia debe ser expresada de forma adecuada para tiempos de persecución, y encuentra su expresión plena en estar en compañía con los mártires.

Deseo y a la vez os exhorto a que... a quienes juntó el mismo vínculo de la confesión común y la comunidad de prisión junte también el lín de la prueba y la corona en el cielo" ${ }^{11}$.

Así, pues, la unidad dentro de la Iglesia está enfocada a partir del martirio, que es la expresión más plena de la unidad dentro de ella, realiza más perfectamente la unión alrededor del obispo y es la meta hacia la que la unidad alienta y anima al pueblo.

Si ponemos juntas todas estas dimensiones de la unidad, resulta que la unidad de la Iglesia viene definida por la obediencia al evangelio en las circunstan- 
cias del día a día. Cuando todo el evangelio es puesto en práctica con fervor, respondiendo a sus exigencias según los tiempos, entonces, se realiza la unidad de la Iglesia. La adhesión a la Iglesia en comunión con el obispo local es un momento indispensable de esa unidad, tanto más necesaria en épocas en que la unidad lleva al martirio.

\subsection{Cómo se expresa la unidad de la Iglesia}

De este enfoque de Cipriano se desprende que la unidad de la Iglesia se lenga que expresar simbólicamente en lodas la dimensiones de la obediencia al evangelio. La unidad de la Iglesia se manifiesta en la armonía de la diversidad. Para Cipriano, por supuesto, el principio de armonía es la vocación al martirio en una Iglesia perseguida, y en este contexto es como entiende la unidad con el obispo.

Cipriano menciona varias manifestacones de fidelidad al evangelio. Insiste en que hay que visitar a los confesores y ayudar a los pobres. Insiste en que los ministros de la Iglesia deben dar muestras de fidelidad moral, y $\rightarrow$ más sorprendentemente- parece presuponer que éstos pueden apelar a visiones y sueños para guiar a los fieles. Pero - como es de esperar- la prueba central de fidelidad es la perseverancia en tiempo de persecución ${ }^{12}$. Si los dirigentes de la Iglesia tienen que ser signos de unidad en ella, deben ser uno con el evangelio y sus exigencias. La eucaristía es también efectiva sólo cuando la celebra una comunidad unida en fidelidad al evangelio.

El Señor se retira cuando se le niega, y no le sirve para su salud al individuo lo que toma, puesto que el sacramento de salvación se les convierte en ceniza, desapareciendo el cuerpo del Señor ${ }^{13}$.

El que la unidad de la Iglesia debe encontrar una expresión simbólica pública explica por qué Cipriano puso tanto énfasis en la reconciliación pública con la Iglesia. Aquélos que renegaron durante la persecución o se adhirieron a comunidades cismáticas habran negado el evangelio, y habian lesionado así la unidad en el corazón de la Iglesia. Por tanto, la restauración de la unidad debe lambién encontrar una expresión simbólica pública.

Cipriano, sin embargo, fue flexible en negociar las formas de reconciliación. Insistió solamente en que se debía tomar en serio la obediencia al evangelio y también en que se debía tener en cuenta la debilidad humana. De ahr que insistió en que los cardos, lapsi, debían cumplir un tiempo de penitencia después de hacer confesión pública de sus pecados, pero se opuso a medidas más severas que pudieran disuadirlos de buscar la reconciliación. Más aún, llegó a ignorar incluso estas exigencias mínimas cuando lo juzgaba oportuno. Asfi, en los comienzos de una persecución, se mostró muy dispuesto a conceder la comunión con la Iglesia, aun en forma acelerada: 
A los que no se apartaron de la Iglesia del Seftor (...) es necesario armarlos y equiparlos para la batalla que está inminente ${ }^{14}$.

Para Cipriano lo que produce unidad y su más alta expresión es el martirio. En una exhoración a los confesores expresa la honda relación entre la unidad de la Iglesia y el martirio.

Esta es otra confesión de vuestra fe que os honra: reconocer que hay una sola Iglesia y no particupar del error o más bien de una maldad extraffa; retomar al mismo campamento de donde salisteis, de donde saltasteis con vigorosa forlaleza para trabar el combate y subyugar al adversario. Debían traerse del campo de batalla los trofeos a este campo, de donde se recibieron las armas para la pelea, para evitar que no tuvieran su gloria en la Iglesia de Cristo aquellos mismos a los que había preparado Cristo para la gloria's

Los mártires son la gloria de la Iglesia porque expresan la unidad de una Iglesia edificada en tomo al evangelio. Por esta razón es tan seductora y peligrosa la tentación de separar mártires e Iglesia. La gloria degenera en vanagloria.

Finalmente, como para Cipriano la unidad de la Iglesia viene definida por la fidelidad al evangelio y es vista desde el martirio, esa unidad no es incompatible con tensiones y desacuerdos, incluso agudos, dentro de la Iglesia En la vida diaria la Iglesia de Cipriano estuvo llena de conflictos, y en algunos lugares de su epistolario llegó a expresar fuerte oposición al obispo de Roma sobre el problema de volver a bautizar a quienes habían renegado de la le en tiempos de persecución. Nunca identificó obediencia al evangelio y unidad con el obispo con sumisión silenciosa a las palabras de un obispo concreto.

\section{La relevancia de Cipriano}

¿Qué nos puede decir hoy Cipriano sobre la relación entre las pequeñas comunidades y la Iglesia universal? Indudablemente su contribución va más allá de afirmar que se debe evitar un cisma formal, por más verdadero e importante que esto sea. $Y$ hay que añadir que, en contra de una interpretación de su teología bastante difundida, Cipriano no alaba una obediencia pasiva al obispo.

De acuerdo a su pensamiento, lo que nos debemos preguntar ante todo al plantear el problema de la unidad debe ser qué exige en nuestro tiempo el seguimiento de Jesucristo y el vivir de acuerdo al evangelio -y eso en términos muy concretos. $Y$ después de identificar qué significa vivir según el evangelio en una determinada época, que nos preguntemos cómo se puede expresar esa vida de manera armoniosa. La unidad con el obispo será entonces un elemento de la expresión pública de un discipulado exigente.

De esta forma, la riqueza del evangelio deberá encontrar una expresión adecuada en prácticas tan diversas como las de dar de comer al pobre, la unidad 
entre los obispos y la celebración de los sacramentos. Todas estas dimensiones eclesiales se deben unificar en tomo a un proyecto concreto que refleje las exigencias del seguimiento de Cristo en nuestros días. En tiempo de Cipriano, el proyecto se basaba en la fidelidad durante la persecución. Por ello, todo lo demás giraba en torno al martirio.

Hoy también, como en tiempo de Cipriano, el proyecto que refleja el evangelio tiene que ser concreto y realista. Cipriano no espiritualizó la vocación al martirio, aunque hubiese conseguido una mayor unidad y paz interna en su Iglesia, si hubiera hablado simplemente de un maruirio "espiritual" y de "sacrificio" personal, en lugar de hablar de derramamiento de sangre. Vio con claridad que el seguimiento tiene que ser expresado en la realidad de la vida diaria y no simplemente en retórica religiosa. $Y$ vio que el obispo estaba obligado a dar aliento a los mártires.

Todo esto nos dice que también hoy nuestro proyecto de Iglesia debe ser concretado en términos prácticos y reales. Me atrevería a afirnar que, para las iglesias que he descrito en la primera parte de este artículo, el proyecto adecuado es el amor preferencial a los pobres. Esto se debe a que la realidad central del mundo en que vivimos es la tragedia de los pobres, y según cómo nos relacionamos con los pobres asi surgirán las exigencias fundamentales del seguimiento de Jesús. Por ello, la unidad de la Iglesia se juega hoy en la respuesta que da a los pobres.

El modo como Cipriano aborda el problema de la unidad sugiere también por qué la opción por los pobres no puede ser exclusiva, pues ella es, precisamente, lo que unifica las múluples formas en que se puede expresar la obediencia al evangelio. Pero, por otra parte, si la opción por los pobres no es tenida en cuenta como lo central, las otras expresiones de obediencia al evangelio, no expresarán de forma vivificante la unidad de la Iglesia.

Si lo que vivifica unidad de la Iglesia es la opción por los pobres, entonces, puede decirse que las pequeñas comunidades que los representan desempeñan el mismo papel en nuestra Iglesia que el que desempeñaban los mártires y los confesores en la Iglesia de Cipriano. Ellos son la gloria de la Iglesia puesto que son la gloria de un evangelio vivo.

Por esta razón sería grave separar de la Iglesia a estas comunidades, pues significarla, en definitiva, perder la gloria de la Iglesia. Enfrentarlas con su obispo y con la unión de los obispos sería, según Cipriano, tan grotesco como enfrentar a los confesores con el obispo.

Pero serfa igualmente pernicioso marginarlas y subordinar su vocación a un ideal abstracto de unidad de la Iglesia, ya que ellas son la gloria de la Iglesia precisamente por su pobreza, así como los mártires fueron la gloria de la Iglesia de Cipriano porque derramaron su sangre. Para Cipriano, cualquier ideal de 
unidad que pase por alto la vocación al martirio resultarfa en fracaso de la obediencia al evangelio. Esto es lo que romperia el fundamento de la unidad de la Iglesia, aun cuando se hiciera en nombre de esa unidad. Lo mismo ocurriría en la actualidad si el llamado al amor preferencial por los pobres quedase subordinado a un ideal absuracto de unidad.

Sigue siendo verdad, sin embargo, que expresar fielmente la unidad de la Iglesia genera tensión - como ocurrió en tiempo de Cipriano-, pues reconocer los signos de los tiempos requiere discemimiento y no a todos los dirigentes y grupos en la Iglesia les ha sido concedido ese don - como sí lo tenia Cipriano. En su tiempo, tampoco los confesores fueron siempre capaces de reconciliar la vocación al martirio con ouras dimensiones del evangelio que habla que expresar públicamente. Por ello no debiera extrailar que nos encontremos hoy en siluaciones similares. Es de esperar que existan desacuerdos y conflictos dentro de la Iglesia, pero hay que añadir que éstos son elementos del proceso por medio del cual se construye la unidad y en el que se llegan a reconciliar los diversos grupos en la Iglesia.

Finalmente, la experiencia y el pensamiento de Cipriano nos muestran que la unidad de la Iglesia es diferenciada. La unidad en la obediencia al evangelio debe expresarse en diversos niveles por grupos diferentes. Cipriano habló de la unidad de los confesores, de la unidad de la Iglesia en tomo al obispo, y de los doce en tomo a Pedro. La unidad en cada uno de estos niveles es importante, y en cada nivel esta unidad debe expresar las múltiples dimensiones del seguimiento. La existencia de las pequentas comunidades en la Iglesia y su vigorosa vida interna constituye, entonces, un don para la Iglesia.

1. De Ecclesiae Unitate 6. En lodas las citas de este artículo seguimos la traducción española en Obras de San Cipriano, BAC (Madrid 1964).

2. Ibid. 4.

3. Ibid. 6.

4. Ibid. 13.

5. Ibid. 14.

6. Epistola 36, 3.

7. Ep. 15, 1.

8. Ep. 28,2.

9. Ep. 58,3.

10. De lapsis 11.

11. Ep.10.5.

12. De lapsis 16.

13. Ep. 57.

14. Ep. 57.

15. Ep. 54,1. 